OPEN ACCESS

Edited by:

John R. Battista,

Louisiana State University, USA

Reviewed by:

Emmanuel F. Mongodin,

University of Maryland, Baltimore,

Paolo De Marco,

CESPU, Portugal

*Correspondence:

Shanmugam Mayilraj

mayil@imtech.res.in

Sanjay K. Bhadada

bhadadask@rediffmail.com

tThese authors have contributed equally to this work.

Specialty section:

This article was submitted to

Evolutionary and Genomic

Microbiology,

a section of the journal

Frontiers in Microbiology

Received: 26 July 2016

Accepted: 18 January 2017

Published: 02 February 2017

Citation:

Chander AM, Nair RG, Kaur G,

Kochhar R, Dhawan DK,

Bhadada SK and Mayilraj S (2017)

Genome Insight and Comparative

Pathogenomic Analysis

of Nesterenkonia jeotgali Strain

CD08_7 Isolated from Duodenal

Mucosa of Celiac Disease Patient.

Front. Microbiol. 8:129.

doi: 10.3389/fmicb.2017.00129

\section{Genome Insight and Comparative Pathogenomic Analysis of Nesterenkonia jeotgali Strain CD08_7 Isolated from Duodenal Mucosa of Celiac Disease Patient}

\author{
Atul M. Chander ${ }^{1,2 t}$, Ramesan G. Nair ${ }^{3 t}$, Gurwinder Kaur ${ }^{3}$, Rakesh Kochhar 4 , \\ Devinder K. Dhawan1, Sanjay K. Bhadada ${ }^{2 *}$ and Shanmugam Mayilraj ${ }^{3 *}$

\begin{abstract}
'Department of Biophysics, Panjab University, Chandigarh, India, ${ }^{2}$ Department of Endocrinology, Postgraduate Institute of Medical Education and Research, Chandigarh, India, ${ }^{3}$ Microbial Type Culture Collection and Gene bank, CSIR-Institute of Microbial Technology, Chandigarh, India, ${ }^{4}$ Department of Gastroenterology, Postgraduate Institute of Medical Education and Research, Chandigarh, India
\end{abstract}

Species of the genus Nesterenkonia have been isolated from different ecological niches, especially from saline habitats and reported as weak human pathogens causing asymptomatic bacteraemia. Here, for the first time we are reporting the genome sequence and pathogenomic analysis of a strain designated as CD08_7 isolated from the duodenal mucosa of a celiac disease patient, identified as Nesterenkonia jeotgali. To date, only five strains of the genus Nesterenkonia (N. massiliensis strain NP1 ${ }^{\top}$, Nesterenkonia sp. strain JCM 19054, Nesterenkonia sp. strain F and Nesterenkonia sp. strain AN1) have been whole genome sequenced and annotated. In the present study we have mapped and compared the virulence profile of N. jeotgali strain CD08_7 along with other reference genomes which showed some characteristic features that could contribute to pathogenicity. The RAST (Rapid Annotation using Subsystem Technology) based genome mining revealed more genes responsible for pathogenicity in strain CD08_7 when compared with the other four sequenced strains. The studied categories were resistance to antibiotic and toxic compounds, invasion and intracellular resistance, membrane transport, stress response, osmotic stress, oxidative stress, phages and prophages and iron acquisition. A total of 1431 protein-encoding genes were identified in the genome of strain CD08_7 among which 163 were predicted to contribute for pathogenicity. Out of 163 genes only 59 were common to other genome, which shows the higher levels of genetic richness in strain CD08_7 that may contribute to its functional versatility. This study provides a comprehensive analysis on genome of $N$. jeotgali strain CD08_7 and possibly indicates its importance as a clinical pathogen.

Keywords: genome sequencing, Nesterenkonia jeotgali, RAST, comparative genomics, celiac disease, pathogenicity, gut 


\section{INTRODUCTION}

The genus Nesterenkonia belongs to the family Micrococcaceae and comprises mesophilic moderate haloalkaliphilic bacteria (Stackebrandt et al., 1995). The members of this genus stain Gram-positive having high genomic G+C content (64-72\%) and are generally aerobic, catalase positive and chemo-organotrophic (Stackebrandt et al., 1995; Collins et al., 2002; Li et al., 2005). The genus is closely related to the genera Micrococcus, Arthrobacter, and Kocuria and cells are usually coccoid or rod-shaped, with or without branching, non-spore-forming and non-encapsulated (Stackebrandt et al., 1995; Govender et al., 2013). Nesterenkonia spp. are found ubiquitously in nature and have been isolated from various environmental niches, including extreme environments like hypersaline soils, soda lakes (Collins et al., 2002; Delgado et al., 2006), hot deserts and saline soils (Li et al., 2004, 2005, 2008). Some strains of Nesterenkonia spp. have been reportedly isolated from effluent treatment plants of paper and cotton pulp mills (Luo et al., 2008, 2009), whereas some were even isolated from feces of AIDS patient (Edouard et al., 2014) and fermented sea food (Yoon et al., 2006). At present, 13 species of genus Nesterenkonia have been validly described (Aidan-Parte, 2014).

Celiac disease (CD) is an autoimmune disorder of the small intestine. Gluten is considered to be the environmental factor responsible for disease pathogenesis but gluten alone is unable to define the disease pathogenesis (Pozo-Rubio et al., 2012). It was reported that the altered intestinal microbiota composition (dysbiosis) is strongly associated with different disease presentation (Nadal et al., 2007; Wacklin et al., 2014). Dysbiosis is caused by early age infections, presence of pathobionts and intake of antibiotics (Cinova et al., 2011; PozoRubio et al., 2013; Sanchez et al., 2013; Canova et al., 2014; Shmidt et al., 2014). As infections are important in CD, they need to be studied thoroughly to understand the host microbe interactions using robust genomic approaches.

Recently we reported unique microbes from CD patients and their description suggested them to be pathogens potentially involved in the disease (Chander et al., 2016a,b). In this study we report another strain designated as $\mathrm{CD} 08$ _ 7 , isolated from the duodenal mucosa of the small intestine and which was provisionally identified as $N$. jeotgali. $N$. jeotgali was initially reported to be isolated from jeotgal, a traditional Korean fermented sea food. N. jeotgali is a non-motile, slightly halophilic and Gram-positive actinomycete which grows optimally at 25$30^{\circ} \mathrm{C}$ in the presence of $2-5 \%(\mathrm{w} / \mathrm{v}) \mathrm{NaCl}$ (Yoon et al., 2006). Although to date, there is no direct previous evidence for the presence or prevalence of $N$. jeotgali in CD patients, phylum Actinobacteria has been known to have a strong relation with the clinical presentations of the CD. Members of this phylum are more abundant in biopsy samples of symptomatic $C D$ patients than in samples of asymptomatic patients (Bustos Fernandez et al., 2014). Interestingly, other Actinobacteria of the family Micrococcaceae (Kocuria kristinae and Rothia mucilaginosa) were more frequent in symptomatic patients as compared to controls whereas absent in asymptomatic patients. Thus, aided by culturomics, Sanchez et al. (2013) described the presence of Micrococcaceae members in CD. Members of phylum Actinobacteria are among the most commonly known bacteria of human duodenum. Though, genus Nesterenkonia has rarely been described in humans but very recently Avilés-Jiménez et al. (2016) observed a higher frequency of Nesterenkonia spp. in benign biliary pathology as compared to biliary tract cancer.

Whole genome sequencing (WGS) of microbes has been used to predict the functional behavior of microbes. In a similar way D'Argenio et al. (2016) not only predicted but validated the WGS predicted pathogenic role of CD gut microbes by a combination with in vitro approaches. They reported Neisseria flavescens strains as the most abundant in symptomatic CD patients. Further, WGS showed these strains possess diverse genetic composition of virulence determinant genes (particularly iron acquisition systems and hemoglobinrelated genes) when compared to those isolated from control subjects. In addition, these strains isolated from patients, were able to escape the lysosomal compartment in Caco-2 cells and to activate inflammatory responses in $\mathrm{CD}$ patients and in ex vivo culture of duodenal biopsies, confirming their possible role in inflammation at the intestinal mucosa. The strain we describe here also possessed several genes for iron acquisition systems and other virulence determinant genes that may also predict its virulence capabilities.

In this study we sequenced the genome of $N$. jeotgali strain CD08_7 for the first time and attempted to map its virulence profile through a comparative genomic approach with the already published genomes of Nesterenkonia species viz. N. massiliensis strain NP1 ${ }^{\mathrm{T}}$, Nesterenkonia sp. strain JCM 19054, Nesterenkonia sp. strain F and Nesterenkonia sp. strain AN1.

\section{MATERIALS AND METHODS}

\section{Bacterial Strain Isolation and Identification}

Strain CD08_7 was isolated from the duodenal mucosa of a $\mathrm{CD}$ patient. The tissues samples from duodenal mucosa were recovered during endoscopy at the Postgraduate Institute of Medical Education and Research, Chandigarh, India. The samples were collected and aseptically transferred to CSIRInstitute of Microbial Technology, Chandigarh. The tissue was homogenized in sterile phosphate saline (PBS) and centrifuged at $4000 \mathrm{rpm}$ for $2 \mathrm{~min}$ to remove debris. The supernatant was recovered and serially diluted with PBS and plated on to tryptic soy agar (TSA; HiMedia, India), incubated at $37^{\circ} \mathrm{C}$ in the presence of oxygen for $36 \mathrm{~h}$. The individual colonies appearing in the plate were picked and plated on to fresh TSA medium which is a broad spectrum medium, further passaged for two times until separate colonies were obtained. The different pure isolates were selected on the basis of distinct cell shape and colony morphology, and these selected strains were identified by $16 \mathrm{~S}$ rRNA gene sequencing. Antibiotic susceptibility tests for strain CD08_7 was performed by placing antibiotic disks (Icosa universal-2, HiMedia, India) on TSA plates seeded with suspensions of strain CD08_7. Characterization of the strain CD08_7 was performed according to the methods described by 


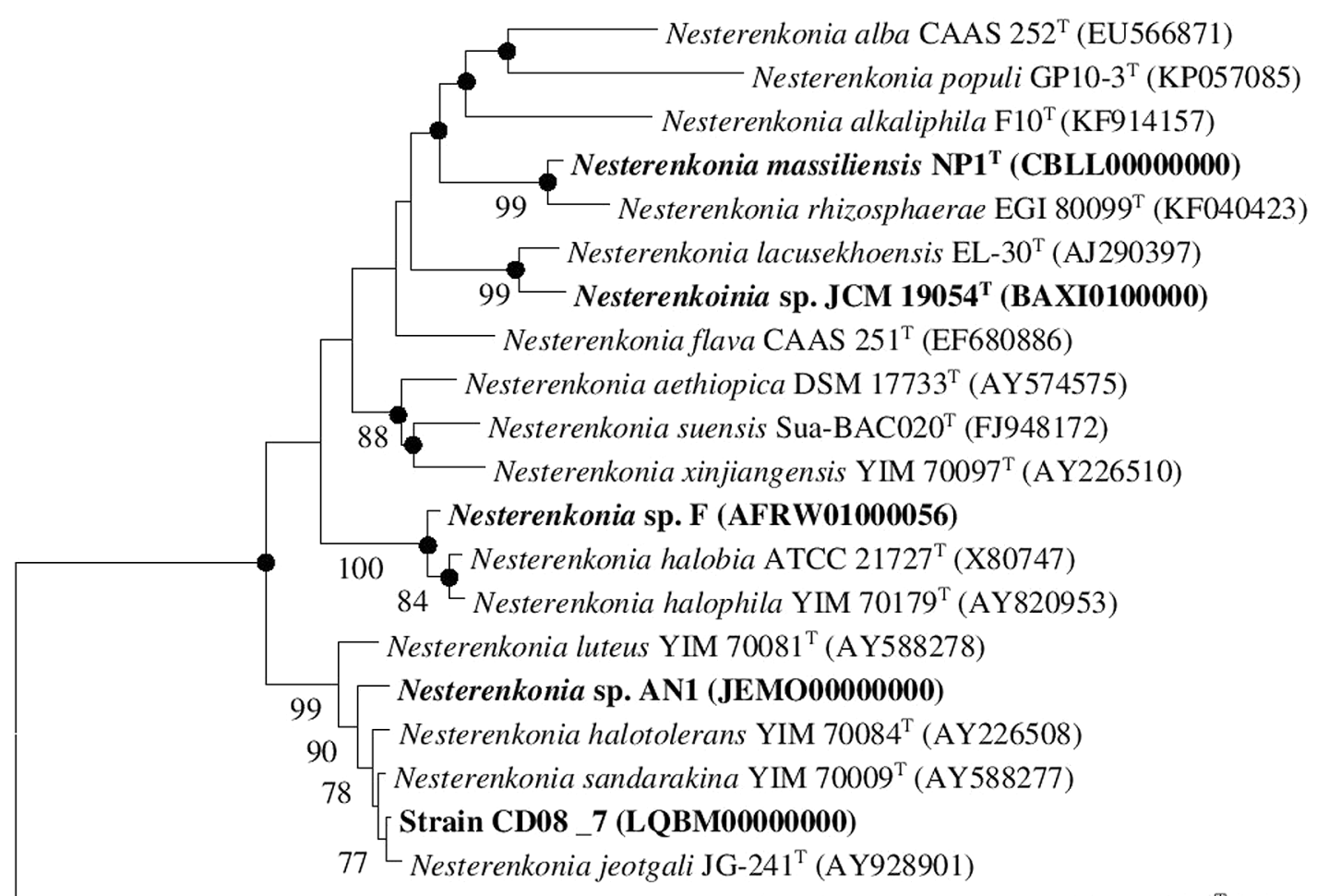

Cellulomonas flavigena DSM $20109^{\mathrm{T}}$ (CP001964)

0.01

FIGURE 1 | Neighbor-joining tree. Neighbor-joining tree based on 16S rDNA sequences, showing the phylogenetic relationship between Nesterenkonia species and other related members of the genus Nesterenkonia. Cellulomonas flavigena DSM 20109' (CP001964) was used as an outgroup Bootstrap values (expressed as percentage of 100 replications) greater than $70 \%$ are given at the nodes. Filled circles indicate that corresponding nodes were also recovered in the trees generated with maximum parsimony and maximum likelihood algorithms. Bar $0.01 \%$ sequence variation.

TABLE 1 | Genome features of strain CD08_7 and other reference strain of genus Nesterenkonia.

\begin{tabular}{|c|c|c|c|c|c|}
\hline Organism & $\begin{array}{c}\text { Nesterenkonia jeotgali } \\
\text { Strain CD08_7 }\end{array}$ & $\begin{array}{c}\text { Nesterenkonia sp. } \\
\text { Strain AN1 }\end{array}$ & $\begin{array}{c}\text { Nesterenkonia sp. } \\
\text { Strain F }\end{array}$ & $\begin{array}{l}\text { Nesterenkonia sp. } \\
\text { Strain JCM } 19054\end{array}$ & $\begin{array}{c}\text { Nesterenkonia }^{\top} \\
\text { massiliensis Strain NP1 }\end{array}$ \\
\hline Accession Number & LQBM00000000 & JEMO00000000 & AFRW00000000 & BAXI00000000 & CBLL00000000 \\
\hline Isolation source & $\begin{array}{c}\text { Duodenal mucosa of CD } \\
\text { patient }\end{array}$ & Salt Lake, Iran & Antarctic soil & $\begin{array}{c}\text { Sea snail Nassarius } \\
\text { glans }\end{array}$ & Feces of AIDS patient \\
\hline Size (Mb) & 2.9 & 3.0 & 2.8 & 2.5 & 2.6 \\
\hline Contigs & 8 & 42 & 138 & 1086 & 175 \\
\hline Scaffolds & 8 & 42 & 138 & 1086 & 19 \\
\hline $\mathrm{G}+\mathrm{C}$ & 67.6 & 67.4 & 71.5 & 67.1 & 62.9 \\
\hline tRNA & 49 & 55 & 50 & 46 & 47 \\
\hline Other RNA & 1 & 1 & 1 & 0 & 1 \\
\hline Number of RNAs & 52 & 52 & 50 & 48 & 49 \\
\hline Number of subsystem & 379 & 374 & 347 & 292 & 355 \\
\hline Coding sequences & 2,531 & 2846 & 2480 & 3901 & 2435 \\
\hline
\end{tabular}

Kaur et al. (2016). Genomic DNA extraction and amplification was performed as previously described (Mayilraj et al., 2006). Identification of phylogenetic neighbors and the calculation of pairwise 16S rRNA gene sequence identity levels were achieved using the EzTaxon server (Kim et al., 2012) and alignments were carried out using Mega version 6.0 (Tamura et al., 2013).
Phylogenetic trees were constructed using the neighbor-joining as well as maximum likelihood and maximum parsimony algorithms. Bootstrap analysis was performed to assess the confidence levels of the branching (Figure 1). The reference genomes of Nesterenkonia strains NP1 ${ }^{\mathrm{T}}, \mathrm{F}, \mathrm{AN} 1$, and JCM 19054 were obtained from the NCBI genome database and bear the 


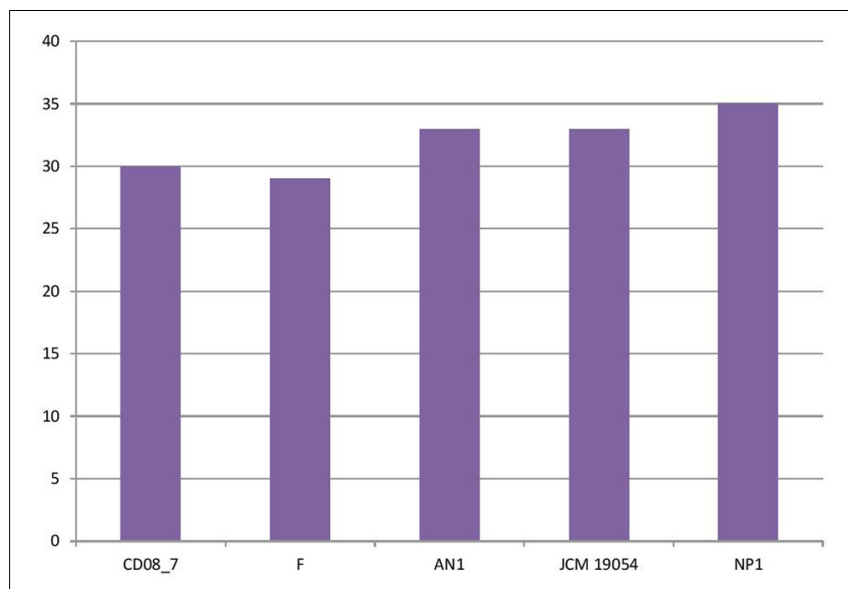

FIGURE 2 | Genes involved in virulence, disease, and defense.

following accession numbers CBLL00000000, AFRW00000000, JEMO00000000, and BAXI00000000, respectively.

\section{Genome Sequencing and Assembly}

A draft genome of strain CD08_7 was sequenced at C-CAMP ${ }^{1}$ next-generation genomics facility, Bengaluru, India using an Illumina HiSeq $2 \times 100$ platform. Library preparation was performed at C-CAMP's genomics facility using TruSeq ${ }^{\circledR}$ DNA sample preparation kit (Illumina) as per manufacturer's instructions. About $1 \mu \mathrm{g}$ of pure genomic DNA was sonicated using Covaris shearing to obtain 300-400 bp fragment size. The resulting fragmented DNA was cleaned up using AMPure $\mathrm{XP}$ beads as described by the manufacturer. Fragmented DNA was subjected to a series of enzymatic reactions that repaired frayed ends, phosphorylated fragments, and added a single nucleotide ' $\mathrm{A}$ ' overhang then ligated adaptors using TruSeq ${ }^{\circledR}$ DNA sequencing kit following the protocol as described by the manufacturer. Sample clean-up was done using AMPure XP beads. After ligation-clean-up, $\sim 300-400$ bp fragments were size selected on 2\% agarose with SYBR Gold gel using TAE Buffer and cleaned using MinElute column, QIAGEN. PCR amplification of adaptor-ligated fragments was done and followed by a cleanup using AMPure XP beads. The prepared libraries were quantified and then validated for quality by running an aliquot on High Sensitivity Bio analyser Chip, Agilent. Assembly was carried out with CLC Bio Workbench v7.5.1 (CLC Bio, Denmark).

\section{Genome Annotation and Comparative Genomics}

The genome annotation for strain CD08_7 was performed using RAST (Aziz et al., 2008; Overbeek et al., 2014; Brettin et al., 2015), which is an automated genome annotation server ${ }^{2}$. Similarly, automated genome annotation for reference genomes of Nesterenkonia strains NP1 ${ }^{\mathrm{T}}$, F, AN1, and JCM 19054 was also

${ }^{1}$ http://www.ccamp.res.in/

${ }^{2}$ http://rast.nmpdr.org/ accomplished using RAST. Further, the ribosomal RNA genes in the genomes were identified using RNAmmer 1.2 (Lagesen et al., 2007). The tRNA and tmRNA genes were identified by ARAGON (Laslett and Canback, 2004). Insertion sequence [IS] elements were identified by the IS finder ${ }^{3}$ (Siguier et al., 2006). The RAST server provides a comprehensive platform for comparing two genomes after their annotation through the seed viewer. Homology search of the protein encoding genes is carried out at protein level using Gene Locator and Interpolated Markov ModelER (GLIMMER 2) against a set of protein families called FIGfams (Aziz et al., 2008). Two genes are considered homologous if they implement the same functional role and the region of similarity shared by them covers over $70 \%$ of each sequence. For further, comparative study of the genomes, the features of $\mathrm{CD} 08$ _ 7 along with the other reference strains of Nesterenkonia were extracted from the RAST server on to an excel sheet and compared manually for presence of unique genes (presence of a gene homolog in strain CD08_7 but it's absence in all other strains was considered as unique), potential pathogenicity determinants, genes involved in metabolic pathways related to virulence (comparative pathogenomics) and common genes among the strains as described previously (Nair et al., 2016).

\section{RESULTS}

\section{Characterization and Phylogenetic Analysis of Strain CD08_7}

The strain designated as CD08_7 matched most of the phenotypic (cocci in shape, non-motile, negative for urease, indole and hydrogen sulfide production, negative for hydrolysis of gelatine and tween 80, nitrate reduction) and chemical [L-Lys-Gly-D-Asp peptidoglycan type, major menaquinones as MK-7 and MK-8 and major lipids as diphosphatidylglycerol (DPG), phosphatidylglycerol (PG), phosphatidyl inositol (PI)] characteristics of the genus Nesterenkonia and most of the features were matched with the species $N$. jeotagli (Yoon et al., 2006; negative for hydrogen sulfide and indole production, while positive for nitrate reduction, hydrolysis of starch, gelatine and tween 80 and for utilization of D-Glucose, D-Xylose, LArabinose, D-Cellobiose, D-Trehalose, Sucrose and Maltose; acid is produced from D-Galactose, D-Xylose and Mannitol, not from Lactose). 16S rRNA gene sequence showed that the strain CD08_7 correspond to the genus Nesterenkonia and is most closely related to N. jeotgali JG241 ${ }^{\mathrm{T}}$ (99.93\% identity; $100 \%$ sequence completeness, one base difference of a total of 1444 bases) followed by N. sandarakina YIM $70009^{\mathrm{T}}$ (99.79\% identity: 99.8\% sequence completeness, three bases difference of a total of 1459 bases), N. halotolerans YIM $7008^{\mathrm{T}}$ (99.73\% identity: $100 \%$ sequence completeness, four bases difference of a total of 1456 bases), N. lutea YIM $70081^{\mathrm{T}}$ (99.38\% identity :100\% sequence completeness, nine bases difference of a total of 1456 bases) and N. xinjiangensis YIM $70097^{\mathrm{T}}$ (97.05\% identity:100\% sequence completeness, 43 bases difference of a total of 1456 bases).

\footnotetext{
${ }^{3}$ http://www-is.biotoul.fr/
} 


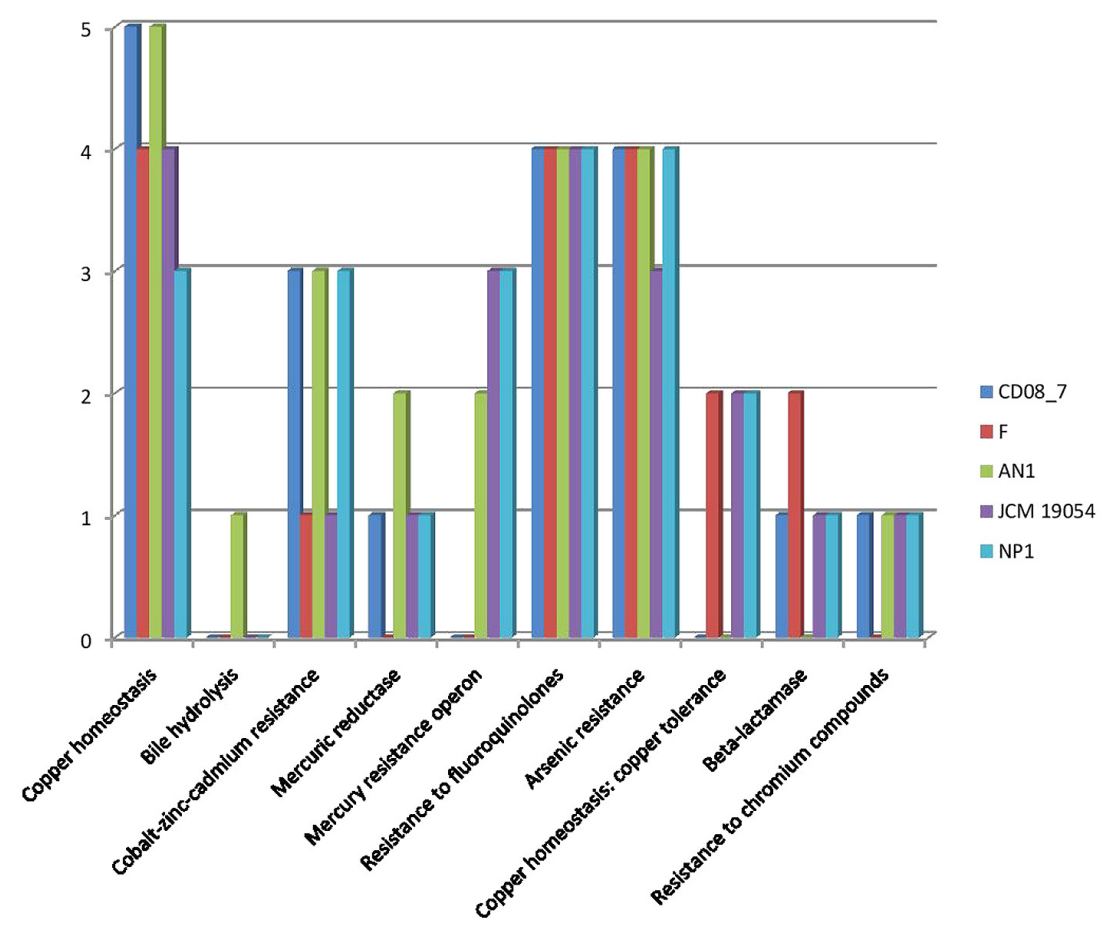

FIGURE 3 | Comparison of genes present in the Nesterenkonia strains involved in conferring resistance against antibiotics and toxic compounds.

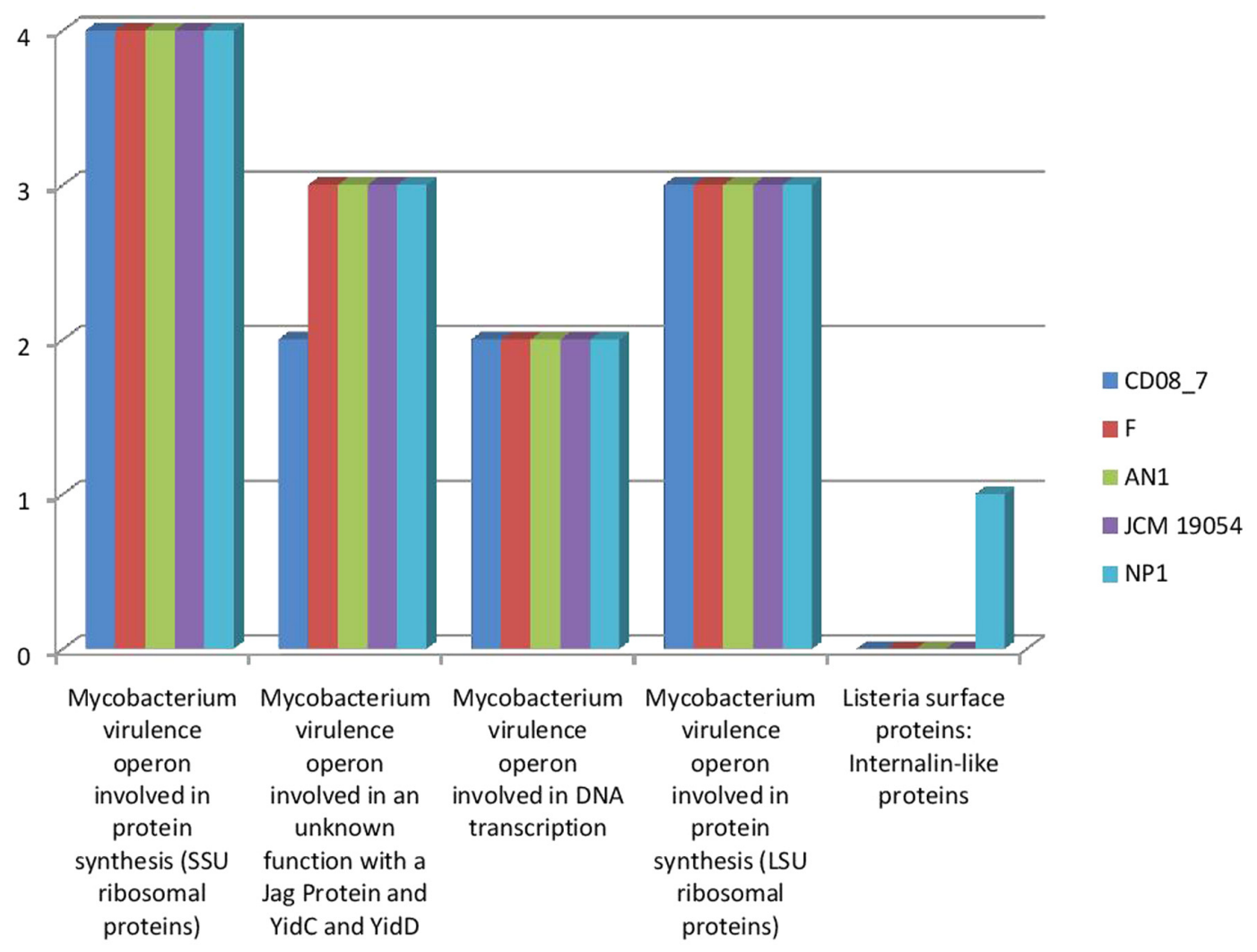

FIGURE 4 | Comparison of gene homologs present in the Nesterenkonia strains involved in invasion and intra cellular resistance. 


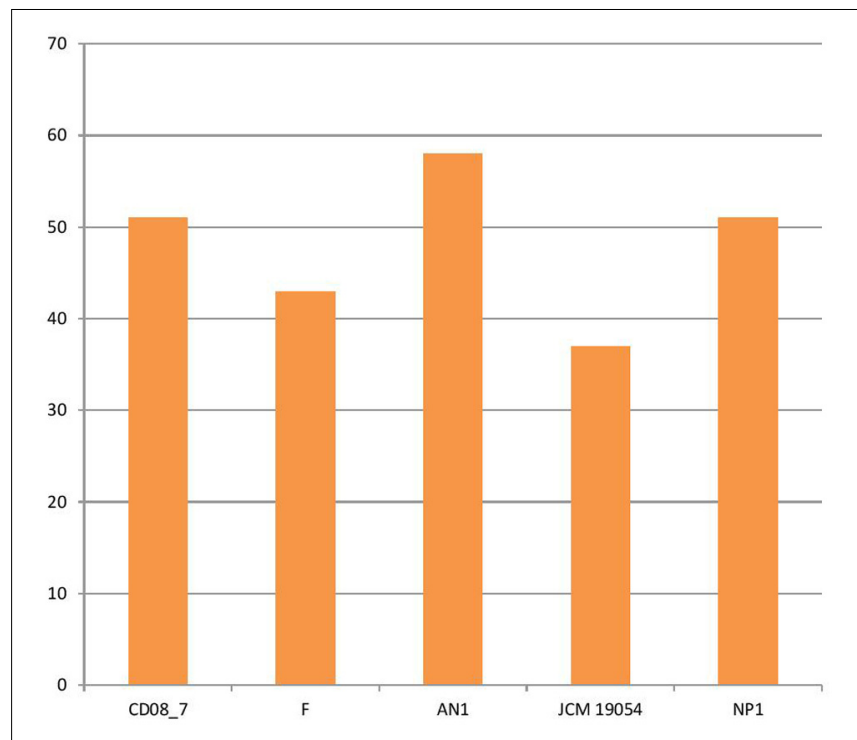

FIGURE 5 | Genes involved in Membrane transport.

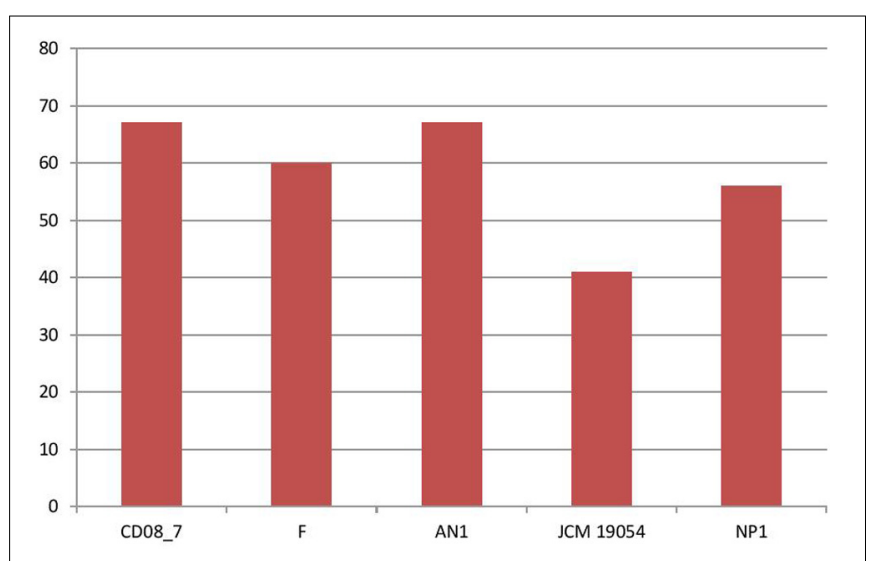

FIGURE 6 | Genes involved in Stress response.

A combined phylogenetic tree (Neighbor joining, Maximum likelihood and Maximum parsimony) of strain CD08_7 was constructed using the 16S rRNA gene sequences of the closely related Nesterenkonia type strains and the reference strains $\mathrm{NP}_{1}{ }^{\mathrm{T}}$, JCM 19054, F and AN1. Strain CD08_7 formed a separate branch with $N$. jeotgali JG- $241^{\mathrm{T}}$; likewise strain $\mathrm{F}$ clustered with N. halobia strain ATCC $21727^{\mathrm{T}}$ and strain AN1 with N. halotolerans strain YIM $70084^{\mathrm{T}}$ (Figure 1).

\section{Genome Features}

The draft genome of strain CD08_7 consisted of 2,925,195 bp with $\mathrm{G}+\mathrm{C}$ content of $67.6 \mathrm{~mol} \%, 2531$ predicted CDSs, 379 sub-systems and 52 RNAs. The final assembly contained eight contigs with $N_{50}$ contig length of 731,296 bp and the largest contig assembled measured $813,259 \mathrm{bp}$. The genome size of Nesterenkonia sp. AN1 was the largest (3.0 Mb) among all genomes (ranging from 2.5 to $2.8 \mathrm{Mb}$ ). Highest genomic $\mathrm{G}+\mathrm{C}$ content $(71.4 \%)$ was of Nesterenkonia sp. strain F, followed by Nesterenkonia sp. strain AN1 (67.94\%), N. jeotgali CD08_7 (67.6\%), N. massiliensis strain $\mathrm{NP1}^{\mathrm{T}}$ (63.0\%), Nesterenkonia sp. strain JCM 19054 (61.1\%). Other genome features of strain CD08_7 along with four reference genomes are shown in Table 1.

\section{Identification of Virulence Determinants}

Genome comparison of N. jeotgali strain CD08_7 was carried out among the other four reference strain of genus Nesterenkonia. The analysis revealed various categories of genes, among which, (1) virulence, disease and defense; (2) phages, prophages, transposable elements and plasmids; (3) stress response; (4) membrane transport and (5) iron acquisition, were further studied because of their extreme importance in contributing pathogenicity. A total of 213 genes were present in the five genomes analyzed had potential to confer pathogenicity. It was surprising to find that strain AN1 (an environmental isolate) had 174 pathogenicity genes. Strain CD08_7 had the second highest number of such determinants (163), strain F had 115, strain JCM 19054 had 123 and strain NP1 had 149. Only 59 of these determinants in strain CD08_7 were common in all the genomes, which shows the functional diversity among species of genus Nesterenkonia. Two genes of phage and prophage origin were unique in the genome of strain CD08_7.

\section{Virulence, Disease, and Defense}

In this category around 30 genes were present in strain CD08_7, when compared to strain $\mathrm{NP}^{\mathrm{T}}$ which had $35, \mathrm{AN} 1$ and JCM $19054^{\mathrm{T}}$ had 33 followed by strain $\mathrm{F}$ which had 29 genes. Two further subcategories were studied under the category Virulence, disease and defense, for their probable contribution in pathogenesis: genes involved in resistance to antibiotics and toxic compounds and genes involved in invasion and intracellular resistance (Figure 2).

\section{Genes Involved in Resistance to Antibiotic and Toxic Compounds}

Resistance to antibiotics and toxic compounds is a primary feature which highlights the organisms as possibly virulent. There are a total of 29 genes present in this subcategory, 19 of which were present in strain CD08_7 whereas 22 in $\mathrm{AN1}$ and $\mathrm{NP} 1^{\mathrm{T}}$. Strain JCM 19054 had 20 of these determinants in its genome, followed by Strain $\mathrm{F}$ that had 17 genes of these determinants in its genome for this subcategory (Figure 3). Strain CD08_7 is resistant to Nalidixic acid (10 $\mu \mathrm{g})$ and sensitive to all other antibiotics of Icosa universal-2 panel, which is in accordance with the presence of mutant genes DNA gyrase subunit B (gyrB) and DNA gyrase subunit A (gyrA). Nalidixic acid inhibits the bacterial growth by damaging DNA replication process after blocking the action of above enzymes (Sugino et al., 1977). Mutations in these genes are supposed to cause resistance in microorganisms due to structural change in the active site of these enzymes. 


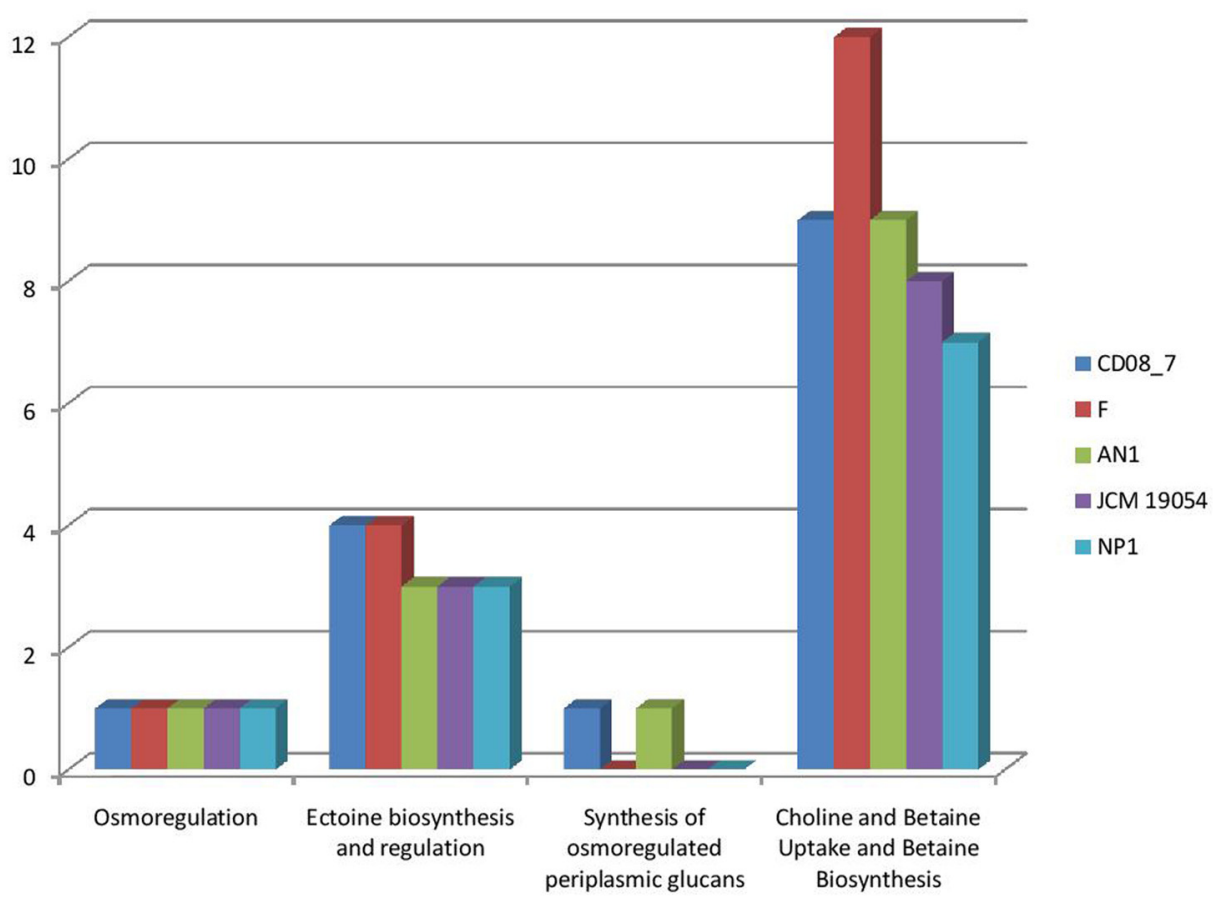

FIGURE 7| Comparison of genes present in the Nesterenkonia strains involved in Osmotic Stress.

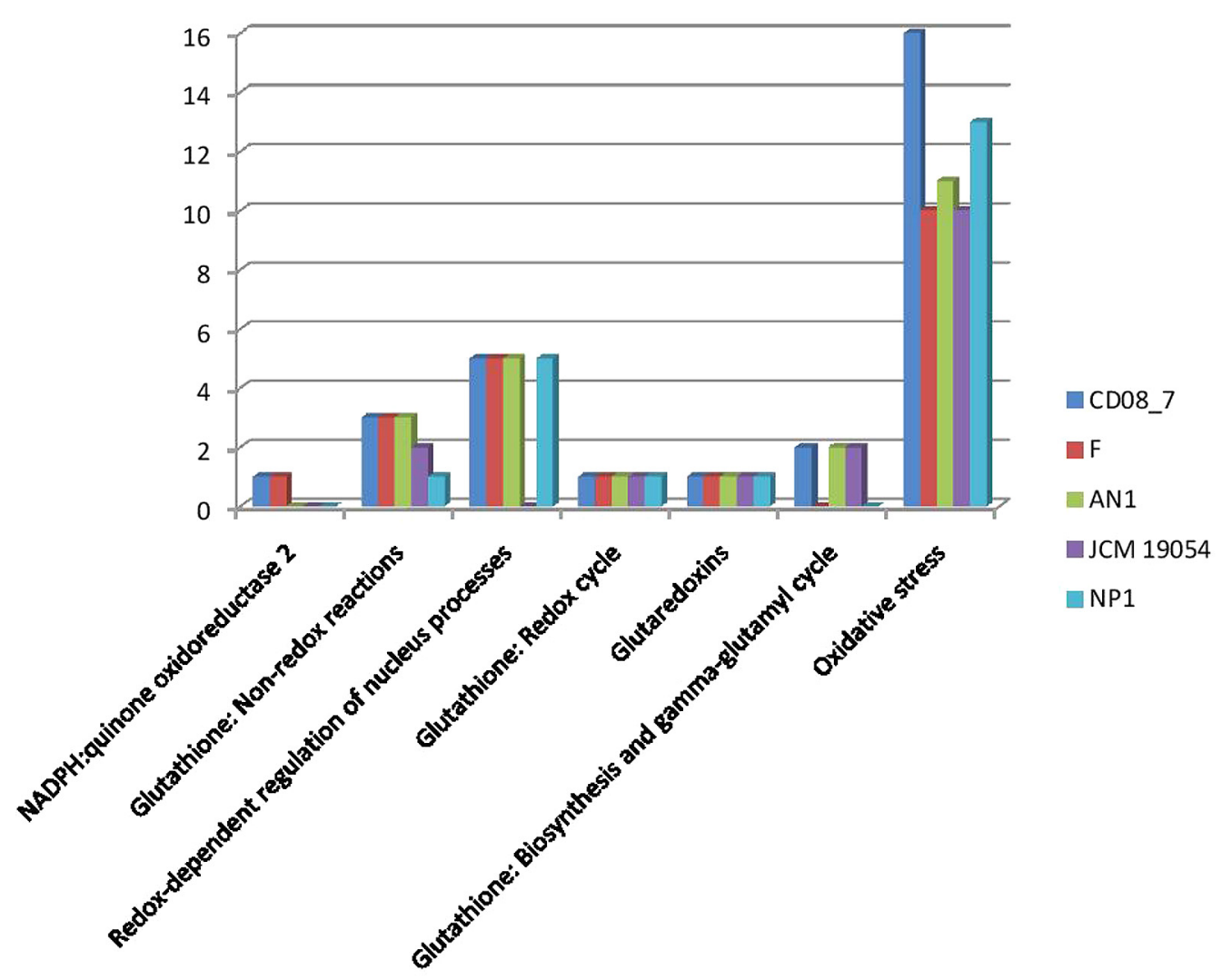

FIGURE 8 | Comparison of genes present in the Nesterenkonia strains involved in Oxidative Stress. 

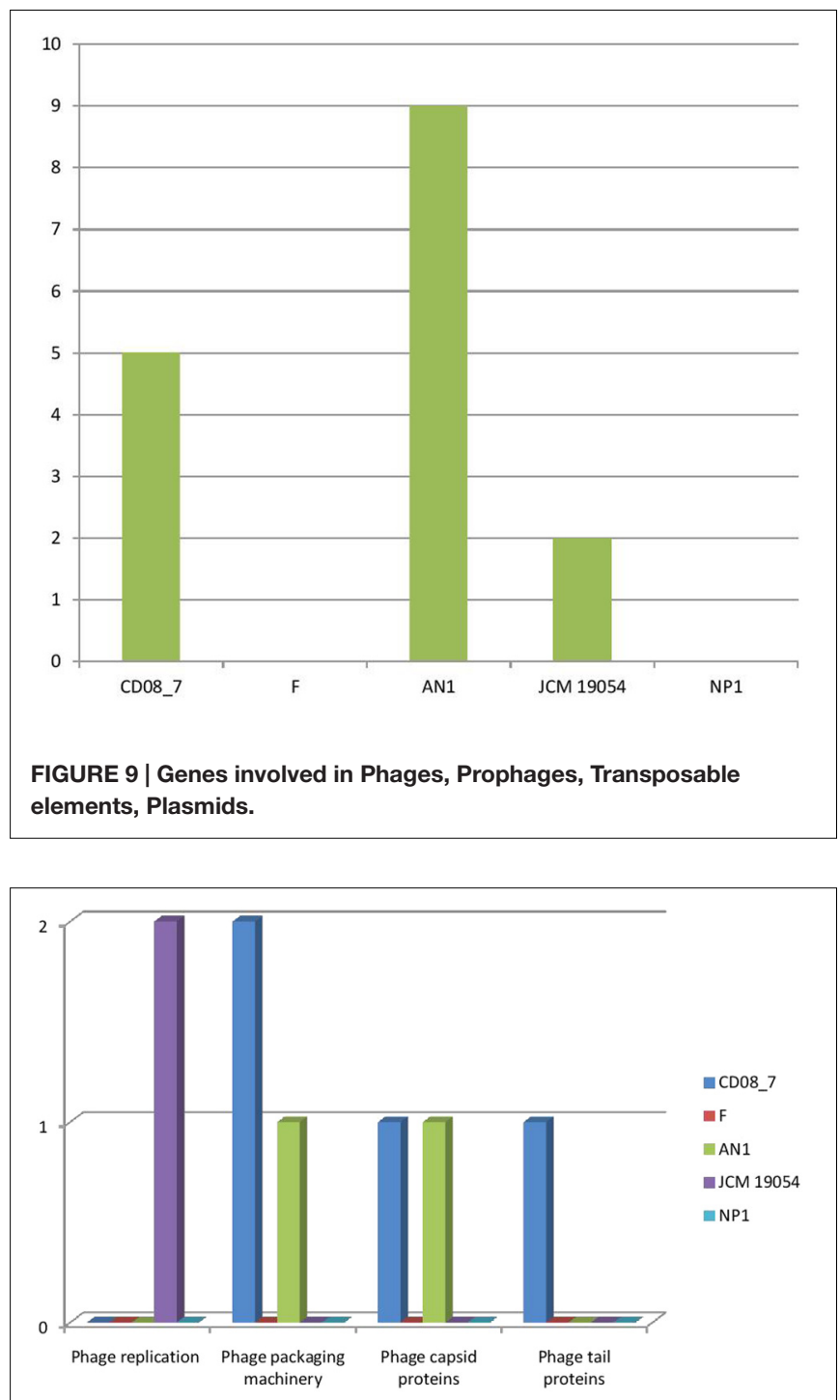

FIGURE 10 | Comparison of genes present in the Nesterenkonia strains involved in Phages, Prophages.

\section{Genes Involved in Invasion and Intracellular Resistance}

Mycobacterium has SSU and LSU ribosomal proteins which contribute in the development of tuberculosis (Nair et al., 2016). This category highlights the presence of these determinants described in Mycobacterium as a characteristic for invading the host and disease progression. Four subsystems were present in strain CD08_7, strain AN1, strain JCM 19054, and strain F whereas strain $\mathrm{NP}^{\mathrm{T}}$ had one gene of an additional subsystem. These results show that strain CD08_7 has the potential to be invasive (Figure 4).

\section{Genes Involved in Membrane Transport}

Several pathogenic bacteria have evolved mechanisms to counteract the host mediated degradation via endocytic pathway,

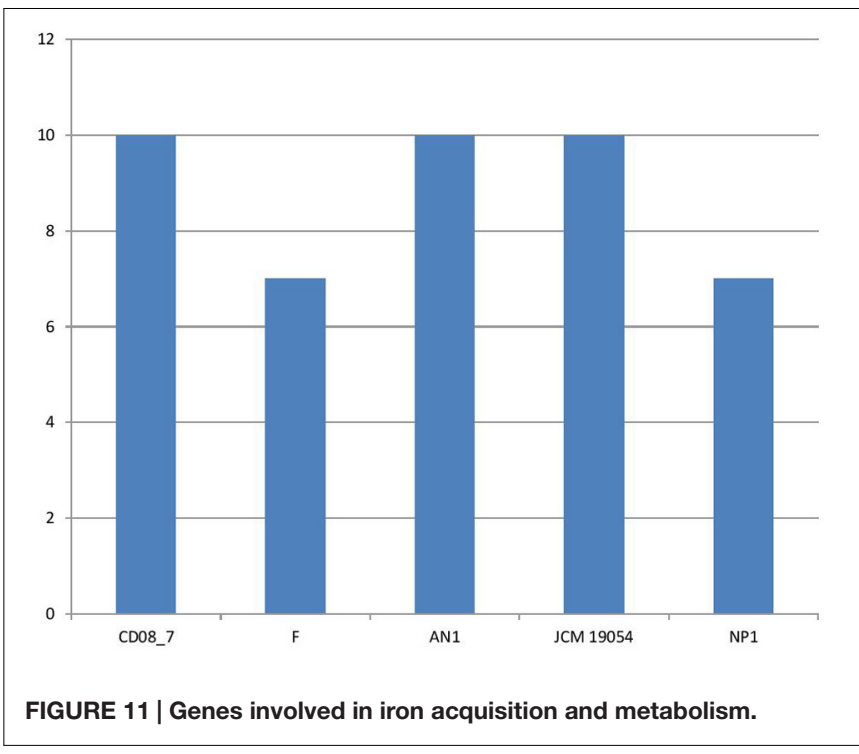

modulating the membrane transport proteins is one such mechanism through which the bacteria are able to use a T3SS (type III secretion system) or T4SS (type IV secretion system) to translocate their proteins across the membrane, where they manipulate the host proteins residing in the cytoplasm. Other bacteria have developed efflux pumps to keep intracellular concentrations of antibiotics low (Alix et al., 2011). Strain AN1 had 58 transport genes in its genome, followed by strains CD08_7 and $\mathrm{NP1}^{\mathrm{T}}$ with 51, strain $\mathrm{F}$ with 43 and strain JCM 19054 with 37. Strain AN1 had some additional transport genes of subcategories, protein secretion system type II (3), ABC transporters (2), TRAP transporters (3) and copper transporters (1) that were absent in CD08_7 (Figure 5).

\section{Stress Response}

Stress response is activated in bacteria when they encounter unfavorable conditions in the host environment. The response mechanism involves adaptation to new conditions by regulation of several molecular pathways that control transcription, translation and post-translation modifications (Rukhsana et al., 1996). Therefore, bacteria having stress response genes in their genomes are able to cope with the oxidative stress produced by human immune cells and osmotic stress due to host osmolytes (Rothe et al., 2012; Paiva and Bozza, 2014). In this category 67 genes were present in strain CD08_7 and AN1, while strain F had 60, strain $\mathrm{NP}^{\mathrm{T}}$ had 56 and JCM 19054 had 41 (Figure 6).

\section{Osmotic Stress Genes}

Osmotic stress is encountered by pathogenic bacteria due to change in the osmolarity while facing adverse osmolyte concentrations. Microbes inhabiting the human intestine face diverse types of osmotic stress exerted by different osmolytes, i.e., carbohydrates, sugars, proteins or fiber components, that can be counteracted by the genes of osmoregulation, if a bacterium contains them (Lucht and Bremer, 1994; Sleator and Hill, 2002; Rothe et al., 2012). Strain CD08_7 possesses four subsystems which may aid it in osmoregulation when facing stress 


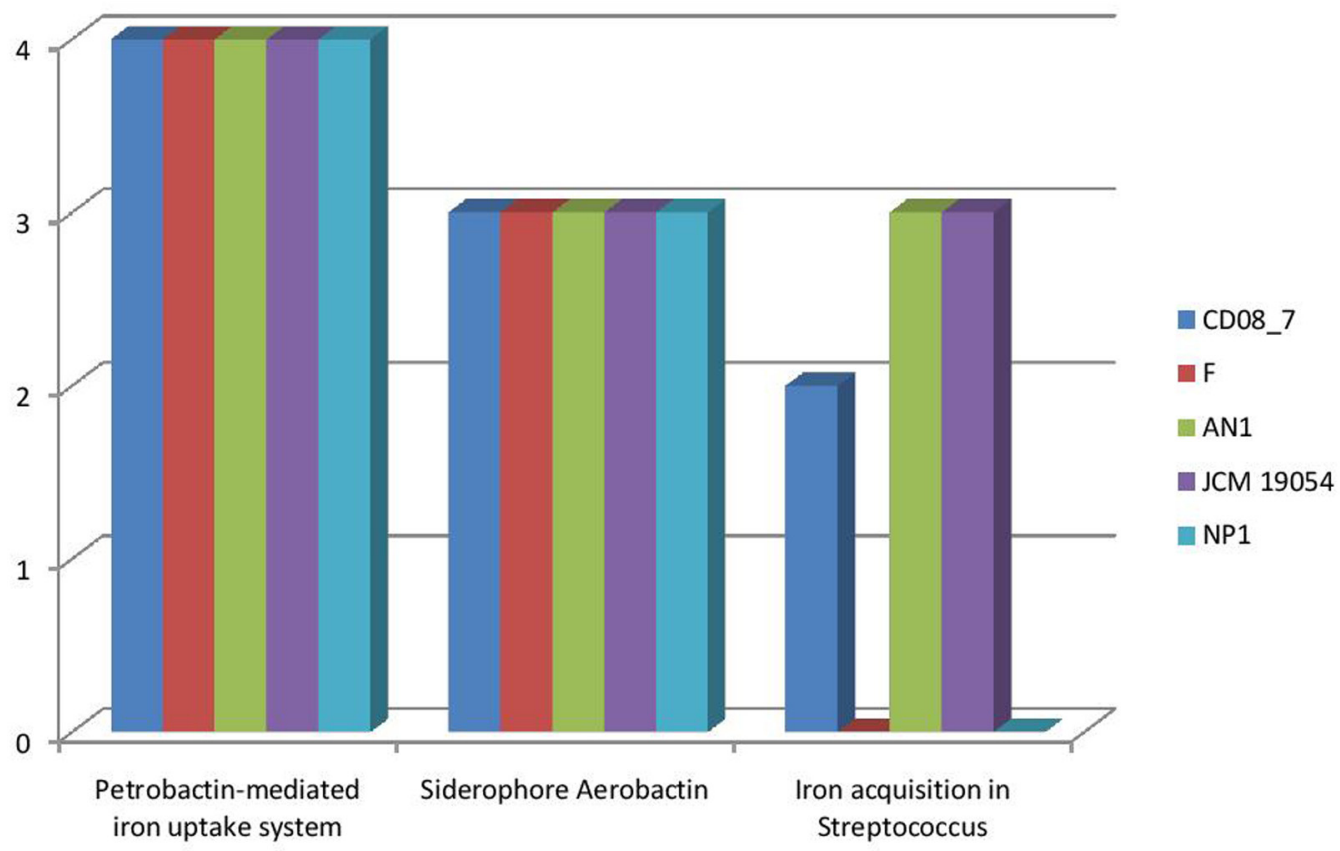

FIGURE 12 | Comparison of genes present in the Nesterenkonia strains involved in siderophores and iron acquisition and metabolism.

conditions. Similarly four sub-systems were present in strain AN1 and 3 in strain NP1 ${ }^{\mathrm{T}}$, JCM 19054 and strain F (Figure 7). Such osmostress responsive systems contribute to the virulence potential of several pathogenic bacteria. The conclusion can be drawn from the above results that strain CD08_7 possesses the potential to sustain osmotic stress in the host.

\section{Oxidative Stress Genes}

The intestinal barrier function of $\mathrm{CD}$ patients is generally dysregulated (Uhde et al., 2014), thus intestinal microbes are expected to get more exposure to phagocytes and other immune cells of the intestinal mucosa. As a defense mechanism against microbes, dendritic cells and B-lymphocytes produce reactive oxygen species (ROS) that cause oxidative stress to inhabiting intestinal microbes (Paiva and Bozza, 2014; Cachat et al., 2015; Stoiber et al., 2015). Interestingly, there are evidences of increased ROS generation at duodenal mucosa of CD patients (Murray et al., 2002; Daniels et al., 2005). Strain CD08_7 contains a total 16 genes which may help it to cope with the oxygen stress in the host environment. Strain $\mathrm{NP}^{\mathrm{T}}$ had 13 such genes followed by AN1 which had 11 while strains F and JCM 19054 had 10 (Figure 8).

\section{Genes of Phages, Prophages, Transposable Elements and Plasmids}

The genes encoding phages, transposable elements and prophages contribute to variability and thus pathogenic success by promoting recombination in bacterial genomes. Strain AN1 contains nine genes in this category, thus strain CD08_7 was second with five followed by strain JCM 19054 which had only two and strains $\mathrm{F}$ and $\mathrm{NP}^{\mathrm{T}}$ had none (Figure 9). Although strain CD08_7 had the highest number of genes (4) in sub-category phages and prophages, it lacked genes for phage replication. The only other strain possessing phage-related genes (just two for replication) was JCM 19054 (Figure 10).

\section{Genes for Iron Acquisition and Metabolism}

It has been shown that iron is essential for growth in bacteria. Within the host bacteria and host cells compete for iron. Bacteria have developed strong mechanisms to capture iron from the host like receptors for eukaryotic iron binding proteins and siderophores, which have high affinity for iron. Therefore, iron acquisition capability is considered as an important measure of pathogenicity associated with any bacterial strain (Baron, 1996). Among the strains analyzed, CD08_7 comprises the highest number of genes related to iron acquisition (10) like strains AN1 and JCM 19054, whereas strains $\mathrm{NP}^{\mathrm{T}}$ and $\mathrm{F}$ had 7 genes (Figure 11). Some of the most important genes in this category were homologs of Streptococcus Siderophore Aerobactin, Petrobactin-mediated iron uptake system and iron acquisition (Figure 12).

\section{DISCUSSION}

The present study analyzed the genome sequence of clinically isolated N. jeotgali strain CD08_7 and revealed several features that highlight it as a probable pathogen. This clinical strain of Nesterenkonia possesses as genetic makeup different from those of the non-clinical strains used here for comparison: it contains higher numbers of genes for virulence (iron acquisition systems, antibiotic resistance, multi drug resistance, oxidative 
stress, and osmotic stress resistance) suggesting adaptation to a host-associated lifecycle. Most of the Nesterenkonia strains described to date are of non-clinical origin and many putative virulence genes have been found in strain CD08_7. This fact suggests that this Nesterenkonia strain is adapted to live in the human intestine and may be relevant in the CD. This study has provided new insights into the pathogenomics of strain CD08_7 which strengthen our suspicion that this strain may be a pathogen associated to CD. We hope that these data will prove beneficial in furthering our understanding of the clinical pathology of this disease.

\section{FUTURE WORK}

This study highlights the attributes of virulence in strain CD08_7 as described by annotated genome sequences and its comparative pathogenomics analysis with reference strains within the same genus. A well planned study focused on determining the prevalence of Nesterenkonia spp./N. jeotgali in duodenal mucosa of $\mathrm{CD}$ and control subjects and its association with disease activity markers and symptoms is still pending. Such a study will allow us to understand the role of this organism and its contribution in the development of CD.

\section{NUCLEOTIDE SEQUENCE ACCESSION NUMBER}

The Nesterenkonia jeotgali strain CD08_7 whole genome shot gun project has been deposited at DDBJ/EMBL/GenBank under project accession number LQBM00000000 locus LQBM01000000 and comprises sequences LQBM01000001-LQBM01000008.

\section{ETHICS STATEMENT}

The study protocol was approved by the Institute's Ethics Committee of Postgraduate Institute of Medical Research and

\section{REFERENCES}

Aidan-Parte, C. (2014). LPSN-list of prokaryotic names with standing in nomenclature. Nucleic Acids Res. 42, D613-D616. doi: 10.1093/nar/ gkt1111

Alix, E., Mukherjee, S., and Roym, C. R. (2011). Subversion of membrane transport pathways by vacuolar pathogens. J. Cell Biol. 12, 943-952. doi: 10.1083/jcb. 201105019

Avilés-Jiménez, F., Guitron, A., Segura-Lopez, F., Mendez-Tenorio, A., Iwai, S., Hernandez-Guerrero, A., et al. (2016). Microbiota studies in the bile duct strongly suggest a role for Helicobacter pylori in extrahepatic cholangiocarcinoma. Clin. Microbiol. Infect. 22, e11-e22. doi: 10.1016/j.cmi. 2015.10.008

Aziz, R. K., Bartels, D., Best, A. A., DeJongh, M., Disz, T., Edwards, R. A., et al. (2008). The RAST Server: rapid annotations using subsystems technology. BMC Genomics 9:75. doi: 10.1186/1471-2164-9-75

Baron, S. (1996). Medical Microbiology, 4th Edn. Galveston, TX: University of Texas Medical Branch.

Brettin, T., Davis, J. J., Disz, T., Edwards, R. A., Gerdes, S., Olsen, G. J., et al. (2015). RASTtk: a modular and extensible implementation of the RAST algorithm for
Education, Chandigarh, India. An informed written consent was obtained from the participant. CD was diagnosed based on serum IgA anti-tissue transglutaminase antibody [tTG-Ab] and duodenal biopsy suggestive of villous atrophy (Oberhuber et al., 1999).

\section{AUTHOR CONTRIBUTIONS}

Performed experiments: RN, AC, and GK; RK provided surgical samples; Planned and executed experiments analyzed data and wrote manuscript: DD, SB, and SM. All authors read and approved the final manuscript.

\section{FUNDING}

We are grateful to Council of Scientific and Industrial Research, New Delhi, India for funding network project "Man as a Super organism: Understanding the Human Microbiome [BSC0119] and partly supported by a project, "Expansion and Modernization of Microbial Type Culture Collection and Gene Bank (MTCC)," jointly supported by the Council of Scientific and Industrial Research (CSIR) Grant No. BSC0402 and Department of Biotechnology (DBT) Govt. of India Grant No. BT/PR7368/INF/22/177/2012. AC, Senior Research Fellow is grateful to Indian Council of Medical Research, New Delhi, India for fellowship. RN and GK are thankful to Council of Scientific and Industrial Research for providing fellowships.

\section{ACKNOWLEDGMENTS}

We are thankful to the patients for participating in the study and allowing us to collect the tissues during their surgical intervention. We thank C-CAMP [http://www.ccamp.res.in/] next generation genomics facility for help in obtaining genome sequences. This is IMTECH communication number 043/2016.

building custom annotation pipelines and annotating batches of genomes. Sci. Rep. 5:8365. doi: 10.1038/srep08365

Bustos Fernandez, L. M., Lasa, J. S., and Man, F. (2014). Intestinal microbiota: its role in digestive diseases. J. Clin. Gastroenterol. 48, 657-666. doi: 10.1097/MCG. 0000000000000153

Cachat, J., Deffert, C., Hugues, S., and Krause, K. H. (2015). Phagocyte NADPH oxidase and specific immunity. Clin. Sci. 128, 635-648. doi: 10.1042/ CS20140635

Canova, C., Zabeo, V., Pitter, G., Romor, P., Baldovin, T., Zanotti, R., et al. (2014). Association of maternal education, early infections, and antibiotic use with celiac disease: a population-based birth cohort study in north-eastern Italy. Am. J. Epidemiol. 180, 76-85. doi: 10.1093/aje/kwu101

Chander, A. M., Kaur, G., Nair, R. G., Dhawan, D. K., Kochhar, R., Mayilraj, S., et al. (2016a). Genome sequencing of serinicoccus chungangensis strain CD08_5 isolated from duodenal mucosa of a celiac disease patient. Genome Announc. 4:e43-16. doi: 10.1128/genomeA.00043-16

Chander, A. M., Nair, R. G., Kaur, G., Kochhar, R., Mayilraj, S., Dhawan, D. K., et al. (2016b). Genome sequence of Kocuria palustris Strain CD07_3 isolated from the duodenal mucosa of a celiac disease patient. Genome Announc. 4:e210-16. doi: 10.1128/genomeA.00210-16 
Cinova, J., De- Palma, G., Stepankova, R., Kofronova, O., Kverka, M., Sanz, Y., et al. (2011). Role of intestinal bacteria in gliadin-induced changes in intestinal mucosa: study in germ-free rats. PLOS ONE 6:e16169. doi: 10.1371/journal. pone. 0016169

Collins, M. D., Lawson, P. A., Labrenz, M., Tindall, B. J., Weiss, N., and Hirsch, P. (2002). Nesterenkonia lacusekhoensis sp. nov., isolated from hypersaline Ekho Lake, East Antarctica, and emended description of the genus Nesterenkonia. Int. J. Syst. Evol. Microbiol. 52, 1145-1150. doi: 10.1099/00207713-524-1145

Daniels, I., Cavill, D., Murray, I. A., and Long, R. G. (2005). Elevated expression of iNOS mRNA and protein in coeliac disease. Clin. Chim. Acta 356, 134-142. doi: 10.1016/j.cccn.2005.01.029

D’Argenio, V., Casaburi, G., Precone, V., Pagliuca, C., Colicchio, R., Sarnataro, D., et al. (2016). Metagenomics reveals dysbiosis and a potentially pathogenic N. flavescens Strain in Duodenum of Adult Celiac Patients. Am. J. Gastroenterol. 111, 879-890. doi: 10.1038/ajg.2016.95

Delgado, O., Quillaguaman, J., Bakhtiar, S., Mattiasson, B., Gessesse, A., and HattiKaul, R. (2006). Nesterenkonia aethiopica sp. nov., an alkaliphilic, moderate halophile isolated from an Ethiopian soda lake. Int. J. Syst. Evol. Microbiol. 56, 1229-1232. doi: 10.1099/ijs.0.63633-0

Edouard, S., Sankar, S., Dangui, N. P., Lagier, J. C., Michelle, C., Raoult, D., et al. (2014). Genome sequence and description of Nesterenkonia massiliensis sp. nov. strain NP1T. Stand. Genomic Sci. 9, 866-882. doi: 10.4056/sigs.5631022

Govender, L., Naidoo, L., and Setati, M. E. (2013). Nesterenkonia suensis sp. nov., a haloalkaliphilic actinobacterium isolated from a salt pan. Int. J. Syst. Evol. Microbiol. 2013, 41-46. doi: 10.1099/ijs.0.035006-0

Kaur, G., Mual, P., Kumar, N., Verma, A., Kumar, A., Krishnamurthi, S., et al. (2016). Microbacterium aureliae sp. nov., a novel actinobacterium member of the genus Microbacterium isolated from Aurelia aurita, the moon Jelly Fish. Int. J. Syst. Evol. Microbiol. 66, 4665-4670. doi: 10.1099/ijsem.0.001407

Kim, O. S., Cho, Y. J., Lee, K., Yoon, S. H., Kim, M., Na, H., et al. (2012). Introducing EzTaxon-e: a prokaryotic 16S rRNA gene sequence database with phylotypes that represent uncultured species. Int. J. Syst. Evol. Microbiol. 62, 716-721. doi: 10.1099/ijs.0.038075-0

Lagesen, K., Hallin, P., Rodland, E. A., Staerfeldt, H. H., Rognes, T., and Ussery, D. W. (2007). RNAmmer: consistent and rapid annotation of ribosomal RNA genes. Nucleic Acids Res. 35, 3100-3108. doi: 10.1093/nar/gkm160

Laslett, D., and Canback, B. (2004). ARAGORN, a program to detect tRNA genes and tmRNA genes in nucleotide sequences. Nucleic Acids Res. 32, 11-16. doi: 10.1093/nar/gkh152

Li, W. J., Chen, H. H., Kim, C. J., Zhang, Y. Q., Park, D. J., Lee, J. C., et al. (2005). Nesterenkonia sandarakina sp. nov. and Nesterenkonia lutea sp. nov., novel actinobacteria, and emended description of the genus Nesterenkonia. Int. J. Syst. Evol. Microbiol. 55, 463-466. doi: 10.1099/ijs.0.63281-0

Li, W. J., Chen, H. H., Zhang, Y. Q., Schumann, P., Stackebrandt, E., Xu, L. H., et al. (2004). Nesterenkonia halotolerans sp. nov. and Nesterenkonia xinjiangensis sp. nov., actinobacteria from saline soils in the west of China. Int. J. Syst. Evol. Microbiol. 54, 837-841. doi: 10.1099/ijs.0.02935-0

Li, W. J., Zhang, Y. Q., Schumann, P., Liu, H. Y., Yu, L. Y., Zhang, Y. Q., et al. (2008). Nesterenkonia halophila sp. nov., a moderately halophilic, alkalitolerant actinobacterium isolated from a saline soil. Int. J. Syst. Evol. Microbiol. 58, 1359-1363. doi: 10.1099/ijs.0.64226-0

Lucht, J. M., and Bremer, E. (1994). Adaptation of Escherichia coli to high osmolarity environments: osmoregulation of the high-affinity glycine betaine transport system proU. FEMS Microbiol. Rev. 14, 3-20. doi: 10.1111/j.15746976.1994.tb00067.x

Luo, H. Y., Miao, L. H., Fang, C., Yang, P. L., Wang, Y. R., Shi, P. J., et al. (2008). Nesterenkonia flava sp. nov., isolated from paper-mill effluent. Int. J. Syst. Evol. Microbiol. 58, 1927-1930. doi: 10.1099/ijs.0.65618-0

Luo, H. Y., Wang, Y. R., Miao, L. H., Yang, P. L., Shi, P. J., Fang, C. X., et al. (2009). Nesterenkonia alba sp. nov., an alkaliphilic actinobacterium isolated from the black liquor treatment system of a cotton pulp mill. Int. J. Syst. Evol. Microbiol. 59, 863-868. doi: 10.1099/ijs.0.003376-0

Mayilraj, S., Saha, P., Suresh, K., and Saini, H. S. (2006). Ornithinimicrobium kibberense sp. nov., isolated from the Indian Himalayas. Int. J. Syst. Evol. Microbiol. 56, 1657-1661. doi: 10.1099/ijs.0.64138-0

Murray, I. A., Daniels, I., Coupland, K., Smith, J. A., and Long, R. G. (2002). Increased activity and expression of iNOS in human duodenal enterocytes from patients with celiac disease. Am. J. Physiol. Gastrointest. Liver Physiol. 283, G319-G326. doi: 10.1152/ajpgi.00324.2001

Nadal, I., Donat, E., Ribes-Koninckx, C., Calabuig, M., and Sanz, Y. (2007). Imbalance in the composition of the duodenal microbiota of children with coeliac disease. J. Med. Microbiol. 56, 1669-1674. doi: 10.1099/jmm.0.47410-0

Nair, G., Gurwinder, K., Indu, K., Nitin, K. S., Sudeep, K. M., Srikrishna, S., et al. (2016). Genome mining and comparative genomic analysis of five coagulasenegative staphylococci (CNS) isolated from human colon and gall bladder. J. Data Mining Genomics Proteomics. 7:192.

Oberhuber, G., Granditsch, G., and Vogelsang, H. (1999). The histopathology of coeliac disease: time for a standardized report scheme for pathologists. Eur. J. Gastroenterol. Hepatol. 11, 1185-1194. doi: 10.1097/00042737-19991000000019

Overbeek, R., Olson, R., Pusch, G. D., Olsen, G. J., Davis, J. J., Disz, T., et al. (2014). The SEED and the rapid annotation of microbial genomes using subsystems technology (RAST). Nucleic Acids Res. 42, D206-D214. doi: 10. 1093/nar/gkt1226

Paiva, C. N., and Bozza, M. T. (2014). Are reactive oxygen species always detrimental to pathogens? Antioxidants \& Redox signaling. Antioxid. Redox Signal. 20, 1000-1037. doi: 10.1089/ars.2013.5447

Pozo-Rubio, T., de Palma, G., Mujico, J. R., Olivares, M., Marcos, A., Acuna, M. D., et al. (2013). Influence of early environmental factors on lymphocyte subsets and gut microbiota in infants at risk of celiac disease; the proficel study. Nutr. Hosp. 28, 464-473. doi: 10.3305/nh.2013.28.2.6310

Pozo-Rubio, T., Olivares, M., Nova, E., De- Palma, G., Mujico, J. R., Ferrer, M. D., et al. (2012). Immune development and intestinal microbiota in celiac disease. Clin. Dev. Immunol. 2012:654143. doi: 10.155/2012/654143

Rothe, M., Alpert, C., Engst, W., Musiol, S., Loh, G., and Blaut, M. (2012). Impact of nutritional factors on the proteome of intestinal Escherichia coli: induction of OxyR-dependent proteins $\mathrm{AhpF}$ and Dps by a lactose-rich diet. Appl. Environ. Microbiol. 78, 3580-3591. doi: 10.1128/AEM.00244-12

Rukhsana, C., Gautam, K. S., and Jyotirmoy, D. (1996). Stress response in pathogenic bacteria. J. Biosci. 21, 149-160. doi: 10.1007/BF02703105

Sanchez, E., Donat, E., Ribes-Koninckx, C., Fernandez-Murga, M. L., and Sanz, Y. (2013). Duodenal-mucosal bacteria associated with celiac disease in children. Appl. Environ. Microbiol. 79, 5472-5479. doi: 10.1128/AEM.00869-13

Shmidt, E., Smyrk, T. C., Boswell, C. L., Enders, F. T., and Oxentenko, A. S. (2014). Increasing duodenal intraepithelial lymphocytosis found at upper endoscopy: time trends and associations. Gastrointest. Endosc. 80, 105-111. doi: 10.1016/j. gie.2014.01.008

Siguier, P., Perochon, J., Lestrade, L., Mahillon, J., and Chandler, M. (2006). ISfinder: the reference centre for bacterial insertion sequences. Nucleic Acids Res. 34, D32-D36. doi: 10.1093/nar/gkj014

Sleator, R. D., and Hill, C. (2002). Bacterial osmoadaptation: the role of osmolytes in bacterial stress and virulence. FEMS Microbiol. Rev. 26, 49-71. doi: 10.1111/ j.1574-6976.2002.tb00598.x

Stackebrandt, E., Koch, C., Gvozdiak, O., and Schumann, P. (1995). Taxonomic dissection of the genus Micrococcus: Kocuria gen. nov., Nesterenkonia gen. nov., Kytococcus gen. nov., Dermacoccus gen. nov., and Micrococcus Cohn 1872 gen. emend. Int. J. Syst. Bacteriol. 45, 682-692. doi: 10.1099/00207713-45-4-682

Stoiber, W., Obermayer, A., Steinbacher, P., and Krautgartner, W. D. (2015). The role of reactive oxygen species (ROS) in the formation of extracellular traps (ETs) in humans. Biomolecules 5, 702-723. doi: 10.3390/biom5020702

Sugino, A., Craig, L. P., Kenneth, N. K., and Nicholas, R. C. (1977). Mechanism of action of nalidixic acid: purification of Escherichia coli nalA gene product and its relationship to DNA gyrase and a novel nicking-closing enzyme. Proc. Natl. Acad. Sci. U.S.A. 74, 4767-4771. doi: 10.1073/pnas.74.11.4767

Tamura, K., Stecher, G., Peterson, D., Filipski, A., and Kumar, S. (2013). MEGA6: molecular evolutionary genetics analysis version 6.0. Mol. Biol. Evol. 30, 2725-2729. doi: 10.1093/molbev/mst197

Uhde, M., Ajamian, M., Caio, G., De Giorgio, R., Indart, A., Green, P. H., et al. (2014). Intestinal cell damage and systemic immune activation in individuals reporting sensitivity to wheat in the absence of coeliac disease. Gut 65, 19301937. doi: 10.1136/gutjnl-2016-311964

Wacklin, P., Laurikka, P., Lindfors, K., Collin, P., Salmi, T., Lahdeaho, M. L., et al. (2014). Altered duodenal microbiota composition in celiac disease patients suffering from persistent symptoms on a long-term gluten-free diet. Am. J. Gastroenterol. 109, 1933-1941. doi: 10.1038/ajg.2014.355 
Yoon, J., Jung, S., Kim, W., Nam, S., and Oh, T. (2006). Nesterenkonia jeotgali sp. nov., isolated from jeotgal, a traditional Korean fermented seafood. Int. J. Syst. Evol. Microbiol. 56, 2587-2592. doi: 10.1099/ijs.0.64266-0

Conflict of Interest Statement: The authors declare that the research was conducted in the absence of any commercial or financial relationships that could be construed as a potential conflict of interest.
Copyright (๑ 2017 Chander, Nair, Kaur, Kochhar, Dhawan, Bhadada and Mayilraj. This is an open-access article distributed under the terms of the Creative Commons Attribution License (CC BY). The use, distribution or reproduction in other forums is permitted, provided the original author(s) or licensor are credited and that the original publication in this journal is cited, in accordance with accepted academic practice. No use, distribution or reproduction is permitted which does not comply with these terms. 